\title{
ARE THE 5CS RELATED TO RISKY BEHAVIOUR: ANALYSIS ACROSS COUNTRIES
}

\author{
Tina Pivec ${ }^{1}$, Ana Kozina ${ }^{1}$, Nora Wiium ${ }^{2}$, \& Fitim Uka ${ }^{3}$ \\ ${ }^{1}$ Educational Research Institute (Slovenia) \\ ${ }^{2}$ University of Bergen (Norway) \\ ${ }^{3}$ University of Freiburg (Germany)
}

\begin{abstract}
The Positive Youth Development approach views youth development from a broader perspective by emphasizing strengths rather than deficits (Catalano, Hawkins, Berglund, Pollard, \& Arthur, 2004). Youth tend to develop more positively when their strengths are aligned with the resources in their environment. Consequently, positive youth development outcomes (5Cs: Competence, Confidence, Character, Connection, and Caring) will be more probable, and risky behaviours less frequent. Since involvement in risky behaviours in adolescence (e.g., substance abuse) can lead to several negative outcomes, it is crucial to understand the relationship between possible protective factors (e.g., 5Cs) and risky behaviours to provide support for at-risk youth. An emphasis was put on the national contexts of Norway, Kosovo, and Slovenia in answering a research question: does this relationship vary across countries? The sample included 218 participants from Slovenia $\left(70.6 \%\right.$ girls; $\left.M_{\text {age }}=17.18\right)$, 220 participants from Norway (47.7\% girls; $M_{\text {age }}=17.30$ ) and 916 participants from Kosovo (Albanians living in Kosovo; $66.3 \%$ girls; $M_{\text {age }}=16.32$ ). 5Cs were assessed by the PYD questionnaire (Geldhof et al., 2013) and additionally, participants answered several questions about risky behaviour (substance abuse, skipping school, etc.). MANCOVA and Factorial ANCOVAs were used. Results show that the 5Cs differ across countries. In addition, a series of Factorial ANCOVAs revealed an interaction effect between countries and alcohol use for Competence, Confidence, and Connection. Guidelines for practice and future research are discussed.
\end{abstract}

Keywords: Positive youth development, 5Cs, risky behaviour, international comparison.

\section{Introduction}

The Positive Youth Development (PYD) framework is based on the Relational Developmental System Theory, which views positive development as an outcome of the interaction between an active, engaged and competent individual and a supportive and nurturing context (i.e., family, school, community, society; Damon, 2004). Thus, in this interaction, positive youth development outcomes (e.g., 5Cs) are more probable while risky behaviours (e.g., substance use, skipping school) are less frequent (Lewin-Bizan et al., 2010).

PYD indicators, operationalized as 5Cs, represent Competence as a positive view of one's actions in specific areas while Confidence is defined as an inner sense of positive self-worth and self-efficacy). Character, the third $\mathrm{C}$ is described as possession of standards for appropriate behaviour with respect to societal and cultural norms. Connection represents positive bonds with friends, family, and institutions, while Caring is a sense of sympathy and empathy for others. A large body of evidence consistently shows that the 5Cs are positively related to adolescent's contribution to self, family and society (e.g., Lewin-Bizan et al., 2010) as well as negatively related to risky behaviours and emotional difficulties (e.g., Jelicic, Bobek, Phelps, Lerner, \& Lerner, 2007).

Due to the negative impact of risky behaviours on adolescents, it is of particular importance to understand the relationship between possible protective factors and risky behaviours in order to design effective interventions. Our aim is to address this relationship in three countries: Slovenia, Norway, and Kosovo to get a deeper understanding of positive youth development outcomes, substance use, and skipping school.

\section{Method}

\subsection{Participants}

The sample included 218 participants from Slovenia $\left(70.6 \%\right.$ girls; $\left.M_{\text {age }}=17.18 ; S D=1.36\right), 220$ participants from Norway $\left(47.7 \%\right.$ girls; $\left.M_{\text {age }}=17.30 ; S D=1.12\right)$ and 916 participants from Kosovo (Albanians living in Kosovo; $66.3 \%$ girls; $M_{\text {age }}=16.32 ; S D=1.67$ ). 


\subsection{Instruments}

The short form of the PYD questionnaire (Geldhof et al., 2013) was used to measure the 5Cs. It consists of 34 items answered on a 5-point Likert scale (with responses ranging from $1=$ strongly disagree to $5=$ strongly agree, for example). Sample items that measure the 5Cs are: Competence (e.g., I do very well in my classwork at school); Confidence (e.g., All in all, I am glad I am me); Character (e.g., I hardly ever do things I know I shouldn't do); Connection (e.g., My friends care about me); and Caring (e.g., When I see another person who is hurt or upset, I feel sorry for them). Reliability measures (Cronbach's alphas) of the 5Cs are adequate: Competence (Slovenia: .65; Norway: .86; Kosovo: .68); Confidence (Slovenia: .89; Norway: .93; Kosovo: .67); Character (Slovenia: .68; Norway: .83; Kosovo: .64); Connection (Slovenia: .73; Norway: .88; Kosovo: .75); Caring (Slovenia: .83; Norway: .90; Kosovo: .85).

Additionally, the participants answered several categorical questions about risky behaviours, from which substance abuse (i.e., Have you used alcohol once or more in the last 30 days? and Have you smoked cigarette once or more in the last 30 days?) as well as skipping school (i.e., Have you skipped school once or more in the last 4 weeks?) were included in the analysis.

\section{Results}

To examine differences in PYD outcomes (i.e., 5Cs) across countries, MANCOVA was employed $\left(\Lambda=0.88 ; F=16.31 ; p<.001\right.$; partial $\left.\eta^{2}=0.06\right)$. In Table 1 , the means of the 5Cs are presented together with standard errors. The post hoc tests revealed that countries significantly differed in all 5Cs; except for Character. Participants from Slovenia reported lower levels of Competence and Caring in comparison with participants from Norway and Kosovo (all $p \mathrm{~s}<.001$ ), lower levels of Confidence with regard to participants from Kosovo $(p<.001)$, and lower levels of Connection compared to participants from Norway $(p=.029)$. The latter reported lower levels of Confidence in comparison with participants from Kosovo $(p<.001)$.

Table 1. 5Cs by Country: MANCOVA.

\begin{tabular}{|c|c|c|c|c|c|c|c|}
\hline \multirow[b]{2}{*}{ Variable } & \multicolumn{6}{|c|}{ Country } & \multirow[b]{2}{*}{$F$} \\
\hline & $\begin{array}{c}\text { Slovenia } \\
M(S E)\end{array}$ & $\begin{array}{l}\text { Norway } \\
M(S E)\end{array}$ & $\begin{array}{c}\text { Kosovo } \\
M(S E) \\
\end{array}$ & $S S$ & $d f$ & $M S$ & \\
\hline Competence & $3.37(.05)$ & $3.61(.05)$ & $3.57(.02)$ & 6.86 & 2 & 3.43 & $7.58 *$ \\
\hline Confidence & $3.62(.05)$ & $3.74(.05)$ & $4.05(.02)$ & 32.15 & 2 & 16.08 & $36.53 * *$ \\
\hline Character & $3.89(.04)$ & $3.97(.05)$ & $3.87(.02)$ & 1.36 & 2 & 0.68 & 1.95 \\
\hline Caring & $4.02(.05)$ & $4.37(.06)$ & $4.23(.03)$ & 11.94 & 2 & 5.97 & $11.61 * *$ \\
\hline Connection & $3.71(.04)$ & $3.87(.05)$ & $3.78(.02)$ & 2.67 & 2 & 1.33 & $3.37 *$ \\
\hline
\end{tabular}

Note. Gender, age and parents' educational background were controlled for; M (SE): Mean (standard error), SS: Sum of Squares; MS: Mean Square; ${ }^{*} \mathrm{p}<.05 ; * \mathrm{p}<.01$.

Due to differences in the 5Cs across countries, we expected the relation between the 5Cs and risky behaviours (i.e., alcohol use, smoking cigarettes, and skipping school) to differ across countries as well. A series of Factorial ANCOVAs were conducted to examine interaction terms between countries and risky behaviours on the 5Cs (Table 2). Only one interaction effect (between countries and alcohol use) was observed on the 5Cs. In particular, participants from Slovenia who have been drinking in the last month were more confident and connected to their society, friends, and parents than those who did not. On the contrary, participants from Kosovo who were drinking in the last month felt less confident and connected than those who did not drink alcohol. For Competence, participants from Slovenia and Norway who have been drinking in the last month felt more competent than those who did not, while participants from Kosovo who have been drinking reported feeling less competent than those who did not drink alcohol.

Table 2. 5Cs and risky behaviours by Country: Series of Factorial ANCOVA Analyses.

\begin{tabular}{lcccc}
\hline & Factorial ANCOVA Summary & & & \\
\hline Source & $S S$ & $d f$ & $M S$ & $F$ \\
\hline Competence & & & & \\
Country*Alcohol & 2.93 & 2 & 1.47 & $2.90^{*}$ \\
Country*Cigarettes & 0.80 & 2 & 0.04 & 0.09 \\
Country*Skipping school & 1.34 & 2 & 0.67 & 1.47 \\
Country*Alcohol & & & & \\
Country*Cigarettes & 3.85 & 2 & 1.93 & $4.39^{*}$ \\
Country*Skipping school & 0.28 & 2 & 0.14 & 0.32 \\
& 2.15 & 2 & 1.08 & 2.45
\end{tabular}




\begin{tabular}{llllll}
\hline Character & & & & \\
& Country*Alcohol & 0.38 & 2 & 0.19 & 0.54 \\
& Country*Cigarettes & 0.63 & 2 & 0.32 & 0.91 \\
& Country*Skipping school & 1.45 & 2 & 0.72 & 2.07 \\
Caring & & & & \\
& Country*Alcohol & 2.00 & 2 & 1.00 & 1.97 \\
$\quad$ Country*Cigarettes & 1.95 & 2 & 0.97 & 1.91 \\
$\quad$ Country*Skipping school & 0.77 & 2 & 0.38 & 0.76 \\
Connection & & & & \\
Country*Alcohol & 5.12 & 2 & .2 .56 & $6.60^{*}$ \\
$\quad$ Country*Cigarettes & 0.03 & 2 & 0.01 & 0.03 \\
$\quad$ Country*Skipping school & 1.07 & 2 & 0.54 & 1.39 \\
\hline
\end{tabular}

Note. Gender, age and parents' educational background were controlled for; SS: Sum of Squares; MS: Mean Square; $* p<.05 ; * *<.01$.

\section{Discussion}

The aim of the paper was to examine differences in the 5Cs across countries, as well as how the relations between PYD outcomes and risky behaviours differed across countries. The results showed that youth reported different levels of 5Cs, especially participants from Slovenia reported lower levels of the 5Cs with respect to the two other countries. Participants from Norway and Kosovo differed only in Confidence, where Norwegians reported lower Confidence. Regarding risky behaviours, the only significant interaction effect occurred for alcohol use. The main differences were between Slovenia and Kosovo, since drinking alcohol in Slovenia is connected to higher levels of Confidence, Competence, and Connection, while participants from Kosovo reported exactly the opposite. Norwegians reported being more competent when drinking alcohol as well.

To our knowledge, comparisons between countries and 5Cs are lacking, especially those regarding the interaction between 5Cs, countries, and risky behaviour. However, in an earlier study, Arbeit et al. (2014) found similar results where a group drinking more alcohol had higher Confidence and Competence than other groups involved in risky behaviours. Moreover, using alcohol does not mean a young person will develop poorly, as Dworkin (2005) reported that experimentation with alcohol could also be an opportunity for positive development, allowing youth to figure out who they are and where they belong. Differences among Slovenia, Norway, and Kosovo appear to reflect cultural and religious contrasts between the countries, since Slovenia and Norway are largely individualistic and Christian countries, while Kosovo is mainly Islamic and collectivistic country.

Despite addressing important youth issues, two of our samples were not large enough. Thus, in addition to larger representative samples, future research could consider more countries and other risky behaviours, such as aggression. Nonetheless, understanding the relations between PYD outcomes and risky behaviours, as well as the contexts in which they occur, may provide additional information on how to tackle pathological drinking and other risk behaviours in youth.

\section{References}

Arbeit, M. R., Johnson, S. K., Champine, R. B., Greenman, K. N., Lerner, J. V., \& Lerner, R. M. (2014). Profiles of problematic behaviors across adolescence: Covariations with indicators of positive youth development. Journal of youth and adolescence, 43(6), 971-990.

Damon, W. (2004). What is positive youth development?. The Annals of the American Academy of Political and Social Science, 591(1), 13-24.

Dworkin, J. (2005). Risk taking as developmentally appropriate experimentation for college students. Journal of adolescent research, 20(2), 219-241.

Geldhof, G. J., Bowers, E. P., Boyd, M. J., Mueller, M. K., Napolitano, C. M., Schmid, K. L., ... Lerner, R. M. (2014). Creation of short and very short measures of the five Cs of positive youth development. Journal of Research on Adolescence, 24(1), 163-176.

Jelicic, H., Bobek, D. L., Phelps, E., Lerner, R. M., \& Lerner, J. V. (2007). Using positive youth development to predict contribution and risk behaviors in early adolescence: Findings from the first two waves of the 4-H Study of Positive Youth Development. International Journal of Behavioral Development, 31(3), 263-273.

Lewin-Bizan, S., Lynch, A. D., Fay, K., Schmid, K., McPherran, C., Lerner, J. V., \& Lerner, R. M. (2010). Trajectories of positive and negative behaviors from early-to middle-adolescence. Journal of Youth and Adolescence, 39(7), 751-763. 